\title{
A Utilização do Brinquedo durante o Tratamento de Crianças com Câncer: Percepções da Equipe Multidisciplinar
}

doi: https://doi.org/10.32635/2176-9745.RBC.2018v64n3.28

The Use of the Toy during the Treatment of Children with Cancer: Perceptions of the Multidisciplinary Team

La Utilización del Juguete durante el Tratamiento de Niños con Cáncer: Percepciones del Equipo

Multidisciplinario

Patrícia Luciana Moreira-Dias'; Isabella Partezani Silva²

Resumo

Introduçáo: $\mathrm{O}$ brincar é uma atividade fundamental na infância e para o desenvolvimento infantil, e deve ser mantida inclusive nas situaçóes de doença e hospitalização. Objetivo: $\mathrm{O}$ objetivo deste estudo foi elucidar a experiência da equipe multidisciplinar com o uso do brinquedo durante o tratamento de crianças com câncer. Método: Trata-se de um estudo qualitativo, realizado em uma instituição que presta assistência especializada a crianças e adolescentes com câncer. Os aspectos éticos da pesquisa com seres humanos foram respeitados. Participaram do estudo dez membros da equipe multidisciplinar que utilizam o brinquedo ou brinquedo terapêutico junto à criança em tratamento oncológico. A coleta de dados utilizou como estratégia a entrevista semiestruturada. As narrativas foram analisadas segundo o referencial da Análise de Conteúdo. Resultados: As experiências compartilhadas revelaram quatro categorias representativas: I. o brinquedo como uma estratégia para que a criança compreenda sobre o universo da doença; II. o brinquedo como um recurso que proporciona segurança para seguir em frente; III. o brinquedo como uma forma de dar voz às emoçóes que não podem ser silenciadas; IV. o brinquedo como uma ponte que aproxima profissionais, criança e família. Conclusáo: Conclui-se que o brinquedo é uma estratégia fundamental de criação e estreitamento do vínculo com a criança e sua família, permitindo que a criança expresse suas vivências e sentimentos. Brincar estabelece uma comunicação que possibilita a compreensão da criança sobre a sua doença e o tratamento como um ser singular.

Palavras-chave: Jogos e Brinquedos; Cuidado da Criança; Neoplasias; Equipe de Assistência ao Paciente.

\begin{abstract}
Introduction: Playing is a fundamental activity in childhood and for child development, which must be maintained even in situations of illness and hospitalization. Objective: The objective of this study was to elucidate the experience of the multidisciplinary team with the use of toy during the treatment of children with cancer. Method: This is a qualitative study carried out in an institution that provides specialized assistance to children and adolescents with cancer. The ethical aspects of human research have been respected. Ten members of the multidisciplinary team that used the toy or therapeutic toy with the child in cancer treatment participated in the study. The data collection used as strategy the semi-structured interview. The narratives were analyzed according to the Content Analysis framework. Results: The shared experiences revealed four representative categories: I. The toy as a strategy for the child to understand about the universe of the disease; II. The toy as a feature that provides security to move forward; III. The toy as a way to give voice to the emotions that can not be silenced; IV. The toy as a bridge approaching professionals, child and family. Conclusion: It is concluded that the toy is a fundamental strategy of creating and narrowing the bond with the child and his family, allowing the child to express their experiences and feelings. Playing establishes a communication that enables the child to understand about his illness and treatment as a singular being. Key words: Play and Playthings; Child Care; Neoplasms; Patient Care Team.
\end{abstract}

\section{Resumen}

Introducción: El juego es una actividad fundamental en la infancia y para el desarrollo infantil, que debe ser mantenida incluso en las situaciones de enfermedad y hospitalización. Objetivo: El objetivo de este estudio fue elucidar la experiencia del equipo multidisciplinario con el uso del juguete durante el tratamiento de niños con cáncer. Método: Se trata de un estudio cualitativo, realizado en una institución que presta asistencia especializada a niños y adolescentes con cáncer. Los aspectos éticos de la investigación con seres humanos fueron respetados. Participaron del estudio 10 (diez) miembros del equipo multidisciplinario que utilizan el juguete o juguete terapéutico junto al niño en tratamiento oncológico. La recolección de datos utilizó como estrategia la entrevista semiestructurada. Las narrativas fueron analizadas según el referencial del Análisis de Contenido. Resultados: Las experiencias compartidas revelaron cuatro categorías representativas: I. El juguete como una estrategia para que el nin̄o entienda sobre el universo de la enfermedad; II. El juguete como un recurso que proporciona seguridad para seguir adelante; III. El juguete como una forma de dar voz a las emociones que no pueden ser silenciadas; IV. El juguete como un puente que acerca a profesionales, niño y familia. Conclusión: Se concluye que el juguete es una estrategia fundamental de creación y estrechamiento del vínculo con el niño y su familia, permitiendo que el niño exprese sus vivencias y sentimientos. Jugar establece una comunicación que permite la comprensión del niño sobre su enfermedad y el tratamiento como un ser singular.

Palabras clave: Juego e Implementos de Juego; Cuidado del Niño; Neoplasias; Grupo de Atención al Paciente.

\footnotetext{
${ }^{1}$ Universidade Paulista (Unip). Jundiaí, (SP) Brasil. Orcid iD: https://orcid.org/0000-0002-3153-5302

${ }^{2}$ Unip. Jundiaí, (SP) Brasil. Orcid iD: https://orcid.org/0000-0002-5883-0838

Endereço para correspondência: Patrícia Luciana Moreira Dias. Avenida Armando Giassetti, 577 - Vila Hortolândia - Trevo Itu - Itatiba. Jundiaí (SP), Brasil. CEP 13214-525. E-mail: patriciamoreira@yahoo.com.
} 


\section{INTRODUÇÃO}

Estimam-se, para cada ano do biênio 2018-2019, 420 mil casos novos de câncer, no Brasil, excluídos os tumores de pele não melanoma. Como o percentual mediano dos tumores pediátricos no Brasil corresponde a cerca de 3\%, depreende-se, portanto, que ocorrerâo aproximadamente 12.500 casos novos de câncer em crianças e adolescentes até os 19 anos ${ }^{1}$.

Do ponto de vista clínico, os tumores pediátricos apresentam etapas de menor latência, em geral crescem rapidamente e são mais invasivos. Entretanto, respondem melhor ao tratamento e são conceituados de bom prognóstico. Os tumores mais frequentes na infância são as leucemias (26\%), seguidos de outros tumores epiteliais (14\%), linfomas (14\%) e tumores do sistema nervoso central (13\%). No Brasil, corresponde à segunda causa de morte entre crianças e adolescentes de 1 a 19 anos $^{1}$.

O tratamento do câncer infantojuvenil é longo e impóe inúmeros desafios para as crianças e adolescentes que o enfrentam. Limitaçóes causadas pela doença e tratamento ocasionam modificaçôes nas atividades habituais da criança e, muitas vezes, a necessidade de hospitalização. Ao ser hospitalizada, a criança é submetida a rotinas e a procedimentos invasivos, desconfortáveis e repetitivos, que lhe causam medo e sofrimento. Além disso, a convivência com amigos e familiares, as açôes de brincar, comer e frequentar a escola sáo restritas durante o tratamento e a hospitalização².

Nesse sentido, existe uma legítima preocupação por parte da equipe de saúde em intervir, de forma a minimizar o sofrimento da criança com câncer, mediante uma abordagem que a considere como um ser em desenvolvimento e com necessidades próprias e singulares. Para isso, a equipe busca estratégias de comunicação eficazes, atividades recreativas e lúdicas, de forma a estreitar o vínculo com a criança, conquistar sua confiança e, principalmente, garantir vivências próprias do seu mundo por intermédio do brincar. São muitas as evidências que sustentam a importância do brincar durante o período de doença e hospitalização. As atividades lúdicas, por meio de brincadeiras, fantoches, jogos, teatro e brinquedo terapêutico são apontadas como estratégias para reduzir o desconforto, medo e ansiedade decorrentes desse contexto de sofrimento. Atualmente, outros recursos têm sido implementados pelas equipes, inclusive os tecnológicos, como jogos e aplicativos.

Os equipamentos eletrônicos são atualmente uma forma de diversão das crianças, sendo uma alternativa interessante no caso das crianças hospitalizadas em tratamento oncológico, as quais muitas vezes estão em uso de medicaçôes ou dispositivos que limitam sua movimentação, ou apresentando sintomas como dor e fadiga, permitindo que realizem essas atividades lúdicas no próprio leito. Assim como os recursos eletrônicos, atividades lúdicas como assistir televisão, desenhos e brinquedos oferecem à criança a oportunidade de resgatar brincadeiras comumente realizadas em casa e mais próximas de sua realidade, melhorando consequentemente sua qualidade de vida, bem-estar e promovendo confiança, distração, interação, tranquilidade e segurança ${ }^{3}$.

O brinquedo terapêutico é uma estratégia com potencial para promover o brincar na situaçáo de doença e tratamento oncológico, incluindo os períodos de hospitalização. Trata-se de uma brincadeira estruturada com a finalidade de aliviar tensôes e ansiedades em decorrência de vivências incomuns à infância. Consiste em desenvolver sessōes que durem entre 15 a 45 minutos, realizadas por um profissional capacitado que já tenha estabelecido uma relação de confiança com a criança. A sessáo de brinquedo terapêutico pode ter como finalidade receber informaçôes sobre procedimentos, doença e hospitalizaçáo, para que a criança expresse seus sentimentos e medos diante da situação que está vivenciando, dramatizando papéis, tendo a oportunidade de brincar com materiais hospitalares e realizar os mesmos procedimentos que nelas serão realizados. Assim, as crianças podem esclarecer suas dúvidas, expressar suas angústias, o que pode, consequentemente, diminuir seus medos $^{4-6}$.

Considerando que o tratamento oncológico demanda de intervençôes de vários profissionais da equipe de saúde e as evidências que compóem o conhecimento sobre a utilização do brinquedo na situaçáo de doença e hospitalização da criança, questiona-se: Quais as percepçôes da equipe interdisciplinar acerca do uso do brinquedol brinquedo terapêutico durante o tratamento da criança com câncer?

O objetivo desta pesquisa foi elucidar a experiência da equipe com o uso do brinquedo/brinquedo terapêutico e identificar qual o seu impacto durante o tratamento da criança com câncer.

\section{MÉTODO}

Trata-se de uma pesquisa com abordagem qualitativa que utilizou, como referencial metodológico, a análise de conteúdo descrita por Morse e Field. Um segmento da entrevista pode consistir em poucas linhas ou em um parágrafo. Codificar significa identificar o conteúdo da entrevista. Os códigos que estấo conectados por significados semelhantes são agrupados, formando categorias. As categorias são identificadas por nomes representativos dos dados que ela contém 7 . 
A pesquisa foi realizada em um hospital pediátrico, no interior do Estado de São Paulo, que presta assistência a crianças e adolescentes de diversas especialidades, sendo uma delas a Oncologia Pediátrica. A equipe é composta por profissionais de diversas áreas; entre elas, médicos especialistas, enfermeiros, fisioterapeuta, nutricionista, assistente social, psicólogos, farmacêutico, dentista, biomédico e pedagogo.

Participaram do estudo dez profissionais da equipe multidisciplinar que utilizavam o brinquedo/brinquedo terapêutico na assistência à criança com câncer, sendo este o critério de inclusão estabelecido. Entre os participantes, três eram enfermeiros, três psicólogos, um fisioterapeuta, um dentista, um nutricionista e um pedagogo. Foram excluídos profissionais em período de férias ou licença. Os elegíveis tinham entre um e sete anos de atuação na área de Oncologia Pediátrica. O número de participantes não foi previamente estabelecido. Seguindo o referencial metodológico, a coleta de dados finaliza-se quando novos dados não emergem das entrevistas e os dados são suficientes para compreensão do objeto de estudo.

Os participantes deste estudo tiveram seus direitos garantidos pautados nos aspectos éticos presentes nas Resoluções do Conselho Nacional de Saúde (CNS) no. 466/2012 e no. 510/2016. Após a aprovação do Comitê de Ética em Pesquisa (CEP) da Universidade Paulista, parecer $n^{\circ}$. 1.674.441, de 8 de agosto de 2016, iniciou-se o processo de coleta de dados. O convite foi feito ao profissional mediante a explicação dos objetivos do trabalho e como seria a sua forma de participação. Perante o interesse em compartilhar sua experiência por meio de uma entrevista, foram fornecidas informaçóes oralmente e por escrito sobre os procedimentos utilizados no desenvolvimento da pesquisa, conforme o Termo de Consentimento Livre e Esclarecido (TCLE). Foi solicitada, aos participantes, a autorização para gravação das entrevistas. Todos concordaram com a gravação.

A coleta de dados foi realizada tendo como estratégia a entrevista do tipo semiestruturada. A entrevista foi orientada pela questáo norteadora: Conte-me como é a sua experiência com o uso do brinquedo ou brinquedo terapêutico na assistência à criança em tratamento oncológico? A partir dessa questão, outras perguntas foram feitas para que fosse alcançada maior profundidade na compreensão da experiência, tais como: Em quais situaçóes você utiliza o brinquedo? Quais dificuldades e facilidades você tem para implementar o uso do brinquedo/brinquedo terapêutico? $\mathrm{Na}$ sua visão, quais os efeitos positivos que o brinquedo traz para as crianças? E para você? Como é a aceitação por parte da criança? E quais as reaçóes que ela manifesta? As narrativas foram gravadas e transcritas na íntegra para, em seguida, serem analisadas de acordo com os passos sugeridos pelo referencial da análise de conteúdo.

Para a análise dos dados obtidos por meio das entrevistas com os profissionais, seguiram-se os passos propostos para análise de conteúdo: codificação e categorização. As entrevistas foram transcritas, codificadas de acordo com seu significado na experiência do profissional. Os códigos conectados por significados semelhantes foram agrupados, formando categorias identificadas por nomes representativos das evidências que ela contempla.

\section{RESULTADOS}

A análise minuciosa dos dados obtidos por meio das entrevistas com os membros da equipe multidisciplinar permitiu a identificação de quatro categorias temáticas representativas da experiência da equipe com o uso do brinquedo/brinquedo terapêutico na assistência às crianças com câncer: (I) $\mathrm{O}$ brinquedo como uma estratégia para que a criança compreenda sobre o universo da doença; (II) $\mathrm{O}$ brinquedo como um recurso que proporciona segurança para seguir em frente; (III) $\mathrm{O}$ brinquedo como uma forma de dar voz às emoçôes que não podem ser silenciadas; (IV) $\mathrm{O}$ brinquedo como uma ponte que aproxima profissionais, criança e família.

\section{BRINQUEDO COMO UMA ESTRATÉGIA PARA QUE A CRIANÇA COMPREENDA SOBRE $O$ UNIVERSO DA DOENÇA}

A chegada da doença impóe à criança novas demandas e adaptaçôes, tais como a realização de procedimentos, consultas, sintomas, medicações com potenciais efeitos desconfortáveis. Nesse contexto, a equipe reconhece que o medo e as incertezas pelo desconhecido são inerentes à experiência.

Para que a criança possa ultrapassar esses momentos difíceis, compreender e aceitar as mudanças em sua vida, os profissionais da equipe multidisciplinar que estáo envolvidos na assistência complexa são fundamentais. A comunicação entre a criança e equipe e o preparo e suporte podem ser realizados de maneira lúdica, já que o profissional considera que o brinquedo é um importante recurso para abordar a criança e ajudá-la a entender o que está acontecendo. Os profissionais utilizam o brinquedo no acolhimento à criança e à família na instituição, minimizando a crença de que o hospital é somente um lugar de sofrimento. Então, o brinquedo passa a fazer parte do cotidiano interacional entre equipe e criança, utilizando esse recurso para a preparaçáo da criança para os procedimentos que não faziam parte do seu universo até então, tais como coleta de líquor, mielograma e biópsias, punção venosa ou inserção do cateter central, sondagens, entre outros procedimentos invasivos e dolorosos. 
Na percepçáo do profissional, ao utilizar o brinquedo na interação com a criança, a compreensão e a aceitação diante do que é proposto para ela naquele momento são vivenciadas com menos sofrimento, pois ela participa ativamente de cada etapa, utilizando no brincar materiais como estetoscópio, seringa e garrote. É por meio do brinquedo e do brincar que o profissional também consegue perceber quais são os seus medos, angústias, dúvidas e ansiedades. Essa compreensão é, para o profissional, mais um recurso para atuar buscando diminuir o sofrimento da criança.

Quando ela entende o que você vai fazer com ela fica tudo mais fácil, porque você tem muito mais a colaboração, e é bonitinho até que depois com o passar do tempo eles repetem as mesmas falas da gente [...] Você vê que ela entende perfeitamente o tratamento dela, ela sabe muito bem do que ela pode e do que ela não pode, nessa hora que você percebe, o quanto de consciência que tem. Você não precisa ter o melhor boneco do mundo, porque você utiliza a imaginaçáo da criança, e tudo é diferente, tudo você consegue transportar para uma outra dimensão (Entrevista 1; Enfermeira).

As crianças, elas tinham uma melhor aceitação, que elas ficavam mais tranquilas durante o procedimento, e então eu entendia que explicar para criança o que ia acontecer era melhor para ela [...] A gente coloca tudo num contexto e cria todo um ambiente para usar. As vezes usando o brinquedo a gente [...]. As vezes náo, muitas vezes, a gente percebe que ele é bom não só pra criança, para os pais também, os pais também vem com uma ansiedade, expectativa do que vai ser, como vai ser feito. É muito termo técnico, são coisas que nem passam pela cabeça dos pais e, quando você usa isso, esse material de verdade, que ele tem oportunidade de manusear de pegar e faz perguntas (Entrevista 2; Enfermeira).

Entáo eu acho que o brincar é muito importante para todas as crianças, para o desenvolvimento global. O brincar no momento da doença é muito significativo [...]. O brincar é muito importante pra criança, eu acho que o brincar é fundamental. Ele é tão importante quanto a medicação. A gente costuma dizer lá na brinquedoteca que isso também é remédio. Faz muita diferença para as crianças e isso acaba refletindo nos pais porque a criança está sempre acompanhada de um adulto, o pai ou a mãe, e à medida que o pai e a máe vê que a criança vem entra na brinquedoteca, acaba esquecendo que aqui é um hospital (Entrevista 6; Psicóloga).

\section{BRINQUEDO COMO UM RECURSO QUE PROPORCIONA SEGURANÇA PARA SEGUIR EM FRENTE}

A experiência de ser uma criança com câncer é permeada por sentimentos de medo e incerteza diante do desconhecido. Os procedimentos, as medicaçóes e as inúmeras mudanças em vários aspectos da vida da criança geram insegurança para a criança e sua família. Para o profissional, mais do que informar e orientar sobre um procedimento, a utilizaçáo do brinquedo promove a segurança para a criança prosseguir na difícil jornada da doença. Com o brinquedo e por meio dele, as crianças tornam-se mais tranquilas, aceitando as mudanças da sua nova condição de vida. A segurança da criança também tem um efeito positivo na família, em especial nos membros que assumem seu cuidado, geralmente os pais. Essa segurança ultrapassa o ambiente hospitalar e ambulatorial, sendo um importante recurso para o profissional ajudar a criança no seu processo de enfrentamento dos medos das angústias incertezas.

E depois a gente verifica quais são os resultados se ajudou a diminuir a irritabilidade a aceitação, como é que a criança se manifestou, então a gente vai preenchendo aos poucos e pergunta pros pais quais são as percepçôes deles depois que a gente inseriu o boneco na vida deles né, e a gente sempre teve uma ótima repercussão, sempre, os pais sempre trazem relatos de que foi muito positivo, entáo eu acredito que é um brinquedo que salva, é isso que eu sinto. [...] Os pais vêm muito assustados né? Entáo você tem que tentar diminuir essa ansiedade de todo mundo, o que eu percebo que com o brinquedo a gente consegue diminuir a tensão de todo mundo (Entrevista 4; Psicóloga).

$\mathrm{Na}$ maioria das fases de reabilitação, eu utilizo bola, cama elástica que acaba sendo um brinquedo também para a criança, utilizamos argolas. Então assim, tem bastante efeito positivo no tratamento, porque muitas vezes eu preciso que a criança fique em pé e ela tem a questáo do medo, da insegurança, entấo muitas vezes eu coloco essa criança em pé e falo, vamos chutar uma bola e ela topa e se eu falo vamos só ficar em pé ela acaba não querendo (Entrevista 10; Fisioterapeuta).

\section{O BRINQUEDO COMO UMA FORMA DE DAR VOZ ÀS EMOÇÕES QUE NÃO PODEM SER SILENCIADAS}

O brinquedo é um importante recurso para o profissional criar um ambiente terapêutico para que a criança possa expressar seus sentimentos, angústias, medos, raiva, e dor, bem como sua alegria, força e resiliência; ou seja, a sua capacidade de resistir e 
lidar com as adversidades e mudanças impostas pela doença e seu tratamento. O brinquedo é um elemento fundamental no processo de comunicação entre a criança e o profissional.

Para o profissional, é pelo brincar que a criança interage com os outros e simula as situaçôes vivenciadas, revelando sua compreensão acerca das experiências. Nesse contexto, o brinquedo terapêutico é uma estratégia importante na assistência. Durante essas sessôes com o brinquedo terapêutico, o profissional permite que a criança manipule os bonecos bem como materiais comumente utilizados pela equipe durante procedimentos, tais como seringas, luvas, gazes e cateteres. Por intermédio desses materiais, as crianças podem reproduzir todos os procedimentos que nelas são realizados, assumindo papéis diferentes entre os profissionais da equipe. Nesse momento, é possível que a criança expresse suas fragilidades e suas forças, que manifeste comportamentos de agressividade ou de ternura.

Ela expressa a forma como compreende algumas interaçóes. Dessa forma, o brinquedo terapêutico é um recurso que proporciona um impacto positivo para a criança, que pode expressar sentimentos e comportamentos, e para o profissional, que pode compreendê-los com maior clareza e redirecionar suas práticas assistenciais.

Essa oportunidade de manusear o próprio objeto e depois ela querer fazer no boneco que é uma forma dela extravasar. $\mathrm{O}$ que faz comigo eu quero fazer com o boneco também. A gente percebe que tem crianças que manifestam mais agressividade, que até seguram a seringa e a agulha como numa forma de arma, que quer atacar. Mas eu entendo que isso seja perfeitamente normal, todo esse processo por qual ela passa de entender que a dor não é causar mal... E ela quer extravasar de alguma forma, tem crianças que depois volta "tia, posso brincar com o boneco?", "tia, deixa eu brincar com o seu boneco?" e eles manipulam, eles querem fazer isso no boneco. Aí faz em casa no irmão também, eu acho que tudo é uma forma de extravasar e de compreensão e de extravasar também sentimentos as angústias, tudo relacionado ao tratamento e aos procedimentos (Entrevista 2; Enfermeira).

E aí, através de uma intervençâo pedagógica com o uso de um brinquedo, de um boneco de fantoche, essa criança teve possibilidade de se abrir, de conseguir interagir, de aceitar esse primeiro contato de se expressar e de mostrar inclusive a possibilidade de se relacionar com outra criança (Entrevista 7; Pedagoga).

\section{BRINQUEDO COMO UMA PONTE QUE APROXIMA PROFISSIONAIS, CRIANÇA E FAMÍLIA}

Por meio do brinquedo, o profissional tem a oportunidade de entrar no mundo da criança, compreender as suas necessidades, emoçôes, medos e dúvidas, e assim conseguir intervir de maneira única, singular, direcionada a cada criança. Além de ser um instrumento que facilita a comunicaçáo do profissional com a criança e da criança com o profissional, desde a simulação de um procedimento até a manifestação de seus sentimentos e vivências, o brinquedo permite a criação e o estreitamento do vínculo entre o profissional, criança e sua família.

O sentimento de medo do desconhecido é vivenciado pelas crianças e, principalmente, em seus familiares quando chegam à instituiçáo trazendo consigo inúmeras dúvidas, receios e ansiedades. $\mathrm{O}$ profissional entâo vai buscar a aproximação com essa criança e com o seu familiar, para que possam criar laços que facilitem e façam com que o tempo de permanência na instituição seja menos traumatizante, de forma a facilitar também a comunicação e a troca de informaçóes.

O profissional, quando utiliza o brinquedo, conquista a criança, mostra que ela poderá ter um momento de distração e prazer, facilitando a sua compreensão e a sua aceitação, e permitindo a construçáo de um vínculo de confiança.

Entáo, quanto mais coisas lúdicas eu trouxer para a instituição e naquele procedimento, eu acredito que aquela criança vai adquirir uma confiança maior em mim, e ela vai saber que naquele momento aquele procedimento, que ela sabe que é doloroso, porque infelizmente é um procedimento doloroso, ele vai ser amenizado com a forma lúdica que a gente trabalha em cima disso. Então a vantagem do brinquedo desse tipo de material é principalmente chegar até a criança abrir essa primeira porta (Entrevista 7; Pedagoga).

Aí eles vão criando vínculos com a instituição, com os profissionais e vai se tornando mais fácil pra gente (Entrevista 10; Fisioterapeuta).

\section{DISCUSSÃO}

Os resultados deste estudo permitiram identificar que a experiência com o uso do brinquedo, pelos profissionais da equipe multidisciplinar, é de extrema importância para que a criança e a família possam compreender o processo da doença e o tratamento, bem como estarem preparados para essa nova rotina e para os procedimentos que serão realizados, que, na maioria das vezes, são os 
que mais causam desconforto nas crianças. As evidências deste estudo corroboram as evidências de outros estudos anteriormente realizados sobre o brinquedo e o brincar na situação de doença e hospitalização.

Estudo sobre a utilização do brinquedo terapêutico e o lúdico na perspectiva da equipe de enfermagem aponta que o brincar também pode ser compreendido como uma possibilidade de expressão de sentimentos, preferências, receios e hábitos; como um mediador entre o mundo familiar e situaçôes novas ou ameaçadoras; uma estratégia de compreensão das experiências desconhecidas ou desagradáveis e de comunicação entre os profissionais e a criança, detectando suas particularidades e possibilitando a criança a revelar seus pensamentos e sentimentos. Nesse sentido, o brincar passa a ser visto como um espaço terapêutico capaz de promover não só a sequência do desenvolvimento infantil, como também a possibilidade de a criança melhor compreender esse momento específico em que vive. Por meio do brincar, podem relacionar-se com o meio e, consequentemente, desenvolveráo sua função social ${ }^{8}$. A brincadeira é uma linguagem universal pela qual as crianças se expressam. Uma conexão adequada entre o brincar e o enfrentamento das crianças em aspectos diversos da vida pode ajudá-las a se desenvolverem e se tornarem mais resilientes ao enfrentar a adversidade?

Percebe-se, pelos resultados deste estudo, que a instituição se manteve como um importante cenário para o brincar durante o tratamento oncológico, promovendo o desenvolvimento infantil e o cuidado à criança em integralidade, e não apenas um cuidado curativo. Concorda-se que os profissionais de saúde, que atuam no cenário hospitalar, precisam desenvolver habilidades para serem facilitadores e promotores da brincadeira no ambiente hospitalar, a fim de proporcionar cuidado mais individualizado e completo à criança, pois tal atividade é essencial para o desenvolvimento infantil ${ }^{10}$.

Estudos apontam que a hospitalização envolve experiências estressantes, entretanto, elas podem ser amenizadas pela presença da família, afetividade da equipe de saúde, informação adequada, atividades recreativas, entre outras. É pelo brincar/brinquedo que acontecem a exploração, as perguntas e as reflexôes sobre o dia a dia e a realidade circundante da criança ${ }^{11}$.

As evidências deste estudo revelam que, para que os profissionais da equipe multidisciplinar possam abordar e trabalhar com essas crianças frente aos seus medos e receios, é necessária a utilização de técnicas que facilitem essa abordagem e comunicação.

Durante a utilização desse brinquedo/brinquedo terapêutico, as crianças tiveram uma maior facilidade para a compreensão e aceitação do que era proposto pelos profissionais, por meio das simulaçóes e dramatizaçóes com os brinquedos e materiais fornecidos, possibilitando assim aliviar suas emoçôes. Estudo realizado com crianças pré-escolares durante o tratamento oncológico demostrou que o brinquedo terapêutico dramático permite momentos de prazer e distração, constitui um refúgio indispensável para que a criança reorganize suas emoçōes após períodos difíceis da vida. $\mathrm{O}$ brinquedo terapêutico pode ser utilizado para auxiliar a criança a ampliar sua capacidade de se relacionar com a realidade, estabelecendo uma ponte entre o mundo real e o mundo vivido, promovendo uma estratégia positiva de enfretamento da situação que vivencia ${ }^{6}$.

Compreende-se com esta pesquisa que o brincar na vida da criança com câncer é de extrema importância para o enfrentamento da doença. Por meio do brincar, a criança se desenvolve em todos os sentidos, promovendo a atividade física e intelectual, satisfazendo suas necessidades afetivas, atuando como uma forma de liberar as suas emoçóes, ajudando a lidar com seus medos, angústias e ansiedades. Uma revisão integrativa reuniu estudos que também demonstram que o uso do brinquedo/brinquedo terapêutico tem sido o foco de atenção de muitos profissionais, pois é uma ferramenta valiosa. Permite que a criança possa expressar suas emoçóes, desejos, frustraçóes e experiências, uma fonte de alívio do estresse, minimizando possíveis traumas. Permite ainda que os profissionais estabeleçam uma comunicação essencial no processo do cuidar, identificando suas necessidades e assim fortalecendo laços de confiança entre eles ${ }^{12}$.

O brincar, na forma de brincadeiras ou do uso do brinquedo terapêutico, tem um importante valor terapêutico para crianças doentes, contribuindo para o seu bem-estar físico e emocional e, consequentemente, para sua recuperação. Dessa forma, corresponde a uma importante ferramenta para os profissionais de saúde diante da vulnerabilidade da criança em tratamento ou vivenciando limitaçôes por doenças ameaçadoras de vida. Brincar no hospital restaura a descontinuidade decorrente da doença, permitindo uma vida mais próxima do normal, mesmo dentro do hospital ${ }^{13}$.

Estudo que teve como objetivo explorar como a criança com câncer utiliza a fantasia, o brincar e o enfrentamento imaginário (que se refere ao uso da imaginaçáo para lidar com as adversidades da doença) revelou que essas atividades possuem um papel significativo no processo de enfrentamento da criança. As crianças usam dessas estratégias para lidar com a doença. A equipe e os pais desempenham um papel significativo nesse contexto, pois a equipe pode, de diversas maneiras, ajudar os pais a responder aos filhos na adaptaçáo para o enfrentamento da situação. O enfrentamento é intensamente interacional, e a criança, um ser ativo nesse processo ${ }^{14}$. 
Este estudo corrobora o constructo teórico acerca do brinquedo e do brinquedo terapêutico como um elemento facilitador para a interaçáo entre a equipe de saúde e a criança, facilitando a ambas a comunicação, o vínculo e a aproximação. Além disso, permite que a criança possa se sentir mais segura diante das adversidades decorrentes da doença e tratamento, compartilhando seus medos e sentimentos.

As limitaçóes do estudo dizem respeito à dificuldade em estabelecer uma nomenclatura para referir-se ao brincar, sendo que, para alguns profissionais, o termo brinquedo terapêutico era o mais próximo da sua realidade; para outros, o lúdico ou ludoterapia, e alguns profissionais referiam-se como brinquedo, jogo ou recreação. Tal fato pode ser explicado por este estudo contemplar profissionais de várias áreas de saber, cada qual com sua fundamentação teórico-prática e linguagem. De maneira geral, percebe-se que, independente da terminologia à qual o profissional se referia, o brincar foi abordado como uma estratégia de aproximação, comunicação e instrução, e, principalmente, pautado em uma intencionalidade comum de promover o alívio do sofrimento da criança.

As evidências deste estudo levantam questôes a serem abordadas em pesquisas futuras, explorando o ambiente interacional para o brincar entre a equipe e a criança, a perspectiva dos pais e das próprias crianças com câncer com relação ao brincar durante o tratamento, assim como estudos que avaliem, por instrumentos e estratégias específicas, o impacto do brincar na redução da ansiedade, promoçáo do conforto e do alívio do sofrimento da criança.

\section{CONCLUSÃO}

O câncer infantojuvenil impõe condiçôes inesperadas e indesejáveis em que a criança se vê fora do seu contexto habitual, como a família, amigos e escola, em razão dos limites que a doença e o tratamento impóem, visto que a criança desconhece esse universo.

$\mathrm{O}$ brinquedo como parte do cotidiano da equipe multidisciplinar e das crianças em tratamento oncológico é uma prática realizada com o intuito de abordar e preparar a criança para esse mundo desconhecido em que foi lançada. O brinquedo nesse contexto serve para que a criança possa entender os processos que irá enfrentar, podendo compartilhar nesses momentos todos os seus medos, angústias, ansiedades e dores.

Ao brincar, as crianças desenvolvem seu papel social e global, desenvolvendo atividades espontâneas, interação com a equipe, criando o vínculo, dramatizando papéis, permitindo assim ao profissional identificar demandas nas quais precisa intervir.
Compreende-se que as percepçóes da equipe que assiste à criança em tratamento oncológico acerca do brinquedo permitiram conhecer o impacto do brincar nas várias situaçôes difíceis que envolvem o tratamento oncológico e a experiência da criança na situação de doença, além dos seus inúmeros benefícios dessa prática.

\section{CONTRIBUIÇÕES}

Patrícia Luciana Moreira-Dias participou da concepção e planejamento do estudo, análise e interpretação dos dados, redação e revisão crítica do manuscrito. Isabella Partezani Silva participou da obtenção, análise e interpretação dos dados e redação do manuscrito.

\section{DECLARAÇÃO DE CONFLITO DE INTERESSES}

Nada a declarar.

\section{FONTES DE FINANCIAMENTO}

Não há.

\section{REFERÊNCIAS}

1. Instituto Nacional de Câncer José Alencar Gomes da Silva. Estimativa 2018: incidência de câncer no Brasil. Rio de Janeiro: INCA; 2017.

2. Silva PL, Xavier GC, Oliveira VV, Figueiredo ML, Prado PF, Aguiar Filho W. Câncer infantil: vivências de crianças em tratamento oncológico. Enferm Foco 2016;7(3/4):51-55.

3. Lima KYN, Santos VEP. O lúdico como estratégia no cuidado à criança com câncer. Rev Gaúcha Enferm 2015;36(2):76-81.

4. Cruz DS, Silva EC, Silva RC, Medeiros RA, Monteiro JP, Araújo AS. Humanização da assistência de enfermagem: relato de caso sobre o uso do brinquedo terapêutico. Rev Ciênc Saúde Nova Esperança 2013;11:47-53.

5. Caleffi CC, Rocha PK, Anders JC, Souza AI, Burciaga VB, Serapião LS. Contribuição do brinquedo terapêutico estruturado em um modelo de cuidado de enfermagem para crianças hospitalizadas. Rev Gaúcha Enferm. 2016 Jun;37(2):e58131.

6. Fonseca MR, Campos CJ, Ribeiro CA, Toledo VP, Melo LL. Revelando o mundo do tratamento oncológico por meio do brinquedo terapêutico dramático. Texto Contexto Enferm 2015;24(4):1112-20.

7. Morse JJ, Field PA. Qualitative research methods for health professionals. Thousand Oaks: SAGE Publications; 1995.

8. Souza LP, Silva CC, Brito JC, Santos AP, Fonseca AD, Lopes $\mathrm{Jr}$, et al. O brinquedo terapêutico e o lúdico na visão da equipe de enfermagem. J Health Sci Inst. 2012;30:354-8. 
9. Capurso M, Ragni B. Bridge over troubled water: perspective connections between coping and play in children. Front Psychol. 2016;7:1953.

10. Silva FL, Cabral EI. O resgate do prazer de brincar da criança com câncer no espaço hospitalar. Rev Bras Enferm. 2015;68(3):391-7.

11. Souza DF, Schueroff LL, Pessoa PR, Sozinho RB. A importância do brincar para as crianças oncológicas na percepção dos cuidadores: em um hospital de referência na cidade de Belém, estado do Pará, Brasil. Rev Pediatr SOPERJ. 2013;14(1):21-25.

12. Cruz DS, Virgínio NA, Maia FS. Therapeutic toy: integrative review. J Nurs UFPE on line. 2013;7(5):1443-8.

13. Koukourikos K, Tzeha L, Pantelidou P, Tsaloglidou A. The importance of play during hospitalization of children. Mater Sociomed. 2015;27(6):438-441

14. Rindstedt C. Children's strategies to handle cancer. Child Care Health Dev 2014;40(4):580-586. 